\title{
'Climategate' scientist speaks out
}

\author{
Embattled climatologist Phil Jones faces his critics.
}

Phil Jones was director of the Climatic Research Unit (CRU) at the University of East Anglia in Norwich, UK, when, last November, more than 1,000 e-mails were illegally obtained from the university and posted on the Internet. Their contents sparked allegations of poor scientific practice at CRU, now the subject of an investigation that was launched on 11 February.

Yet until recently, Jones had remained almost silent on the affair, despite being vilified by critics and even receiving death threats. It's no wonder that in an interview with Nature last week, he spent much of his time with his arms crossed tightly in front of his chest, as if shielding himself from further attack.

One issue now under investigation is whether Jones or his CRU colleagues ever published data that they knew were potentially flawed, in order to bolster the evidence for man-made global warming. Under scrutiny is one of Jones's research papers (P. D. Jones et al. Nature 347, 169-172; 1990) on whether the apparent rise in temperature readings in the late twentieth century could be an artefact of measurement sites that shifted from the countryside to cities, which are warmer. The study concluded that this 'urban heat island' effect was negligible, and that the dominant effect was global climate change.

Jones and his co-authors used data from weather stations around the world; those in China "were selected on the basis of station history: we chose those with few, if any, changes in instrumentation, location or observation times", they wrote. But when this claim was questioned in 2007, it became clear that the raw data were obtained from a Chinese contact of one of Jones's co-authors, Wei-Chyung Wang of the University at Albany in New York, and details of the

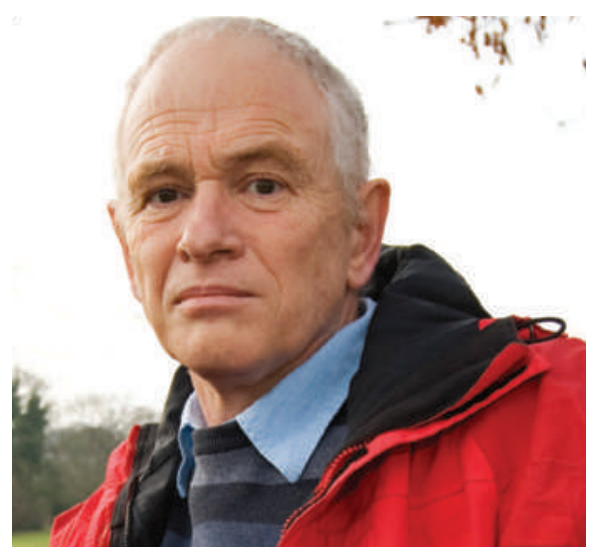

Phil Jones stands by his research.

stations' locations had subsequently been lost.

"I thought it was the right way to get the data," Jones says, but he now acknowledges that "the stations probably did move", and that not having a detailed history of stations' locations was sloppy. "It's not acceptable," he says. "[It's] not best practice." Despite this, Jones says that follow-up studies (P. D. Jones, D. H. Lister and Q. Li J. Geophys. Res. 113, D16122; 2008) verified the original conclusions for the Chinese data for the period 1954-83, showing that the precise location of weather stations was unimportant.

Jones says that he did not know that the stations' locations were questionable when they were included in the paper, but as its lead author he acknowledges his responsibility for ensuring the quality of the data. Asked if he will submit a correction to Nature, he replies: "I will give that some thought. It's worthy of consideration."

Jones rejects other allegations that he has selectively used data from tree rings - the thickness of which reflect annual temperatures and rainfall - to play down the importance of the Medieval Warm Period (MWP), a phase of natural warming that may have occurred 1,000 years ago. If the MWP was restricted to mild local warming, it would mean that present-day global warming is unprecedented for the past 1,000 years.

Scientists agree that the past 40 years of treering data are unreliable temperature proxies, and some argue that using them in older temperature reconstructions, as Jones has done, could understate past warm periods, including the MWP (see Nature 463, 284-287; 2010). "It potentially does," admits Jones, but he adds that analyses using other methods - proxy temperature markers from ice-core samples, for example - still show much the same temperature change over the past millennium.

Jones, an author on the most recent climate assessment report of the United Nations' Intergovernmental Panel on Climate Change (IPCC), also denies trying to censor dissenting voices but defends the right of IPCC authors to exclude papers if they are scientifically weak or irrelevant. "The IPCC [report] is an assessment, it's not a review," he says.

But he fears that this message, and the broader evidence for man-made climate change, is being lost in the aftermath of the 'climategate' affair as blogs and media reports dominate the debate. Jones is emphatic that climate researchers should speak out to defend their research. "[I'd] like to see the climate science community supporting the climate science more," he says. "Lots of them are trying but they're being drowned out." Olive Heffernan

See go.nature.com/RcDkAk for the full interview.

\section{Asian pollution delays inevitable warming}

The grey, sulphur-laden skies overlying parts of Asia have a bright side - they reflect sunlight back into space, moderating temperatures on the ground. Scientists are now exploring how and where pollution from power plants could offset, for a time, the greenhouse warming of the carbon dioxide they emit.

A new modelling study doubles as a thought experiment in how pollution controls and global warming could interact in China and India, which are projected to account for $80 \%$ of new coal-fired power in the coming years. If new power plants were to operate without controlling pollution such as sulphur dioxide $\left(\mathrm{SO}_{2}\right)$ and nitrogen oxides $\left(\mathrm{NO}_{x}\right)$, the study finds, the resulting haze would reflect enough sunlight to overpower the warming effect of
$\mathrm{CO}_{2}$ and exert local cooling.

But this effect would not be felt uniformly across the globe and would last only a few decades. In the long run, $\mathrm{CO}_{2}$ would always prevail, and the world could experience a rapid warming effect if the skies were cleaned up decades down the road.

"The paper highlights the fundamental inequity and iniquity of anthropogenic climate change: 'enjoy now and make others pay later'," says Meinrat Andreae, an aerosol expert at the Max Planck Institute for Chemistry in Mainz, Germany, who was not involved in the work. In fact, he says, dirty coal plants could be seen as "a very primitive form of geoengineering".

The study, which is under review at Atmospheric Chemistry and 


\section{Trees spit out gas from soil microbes}

The atmospheric concentration of methane, a greenhouse gas with 25 times the heating power of carbon dioxide, has more than doubled over the past 200 years. Researchers have long known that methane comes from anaerobic processes in waterlogged soils such as swamps, wetlands and rice fields, as well as in the guts of termites and ruminant animals such as cows and sheep. But in 2006, a team proposed the surprising idea ${ }^{1}$ that plants, too, produce methane - as much as $10-30 \%$ of the world's total methane emissions. If true, that would require a major overhaul of global carbon budgets.

Now a study suggests that trees can act like chimneys, moving methane gas produced by soil microbes up through roots, stems and leaves before releasing it into the atmosphere. This effect could account for as much as $10 \%$ of methane emissions globally ${ }^{2}$. It could also help to explain why methane fluxes are higher than expected in wet tropical regions.

Ellen Nisbet, an evolutionary biologist at the University of South Australia in Adelaide, previously reported that plants do not have the biochemical pathways needed to generate methane. "I'm pretty sure from our studies that [plants] aren't making methane themselves," she says. "This paper is really showing that methane is moving around the plants, that it's being transported up and out."

The team responsible for the latest work, led by atmospheric scientist Andrew Rice of Portland State University in Oregon, measured methane flow in three tree species, which were flooded to create conditions ripe for anaerobic microbes to start churning out methane.

Rice says that the work does not rule out

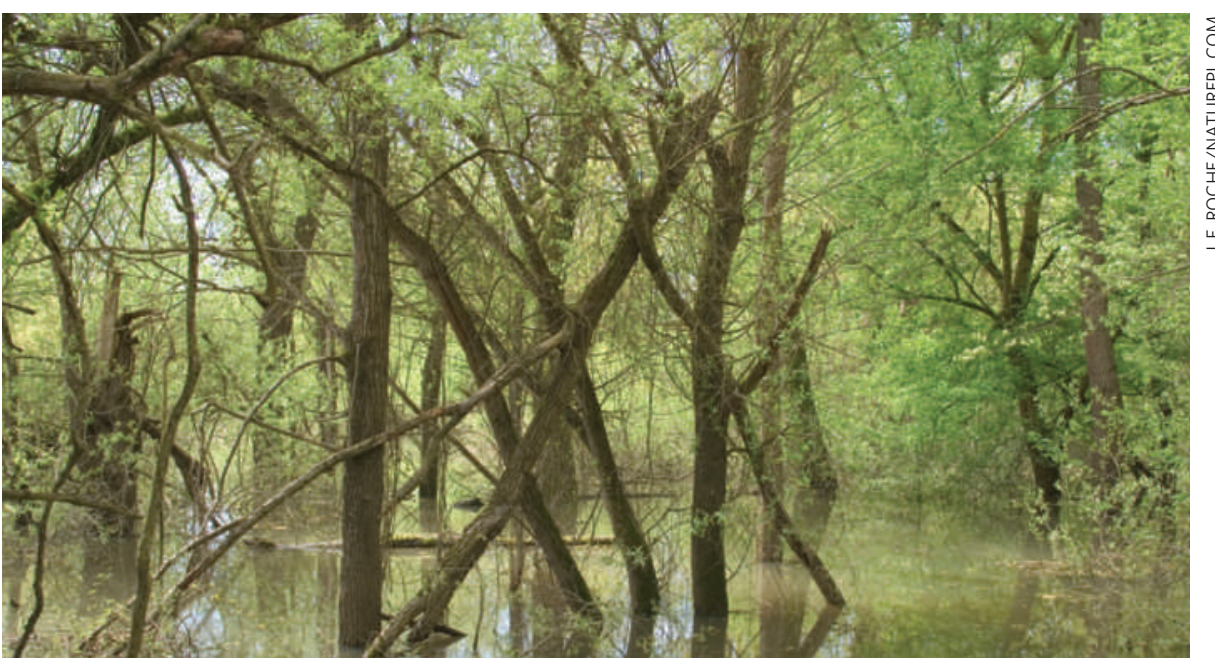

Waterlogged soils provide the perfect environment for methane-producing soil bacteria.

the possibility that plants themselves can produce methane aerobically; for instance, light at a certain intensity and wavelength could create a photolytic reaction that produces methane, as the 2006 work suggested. "The question is the magnitude of that source," says Rice.

The latest study also found that the isotopic composition of the microbial methane transported through the trees was almost identical to that of the methane emissions observed in the 2006 study. This means that it could be tough to distinguish in the field between methane produced anaerobically and that produced aerobically.

The idea of aerobic methane production "is still a hard pill for a lot of scientists to swallow", says Patrick Megonigal, a biogeochemist at the Smithsonian Environmental Research Center in
Washington DC. “This paper shows that there are other mechanisms that we understand a little better, which could give you the same isotopic ratio and fit into the budget nicely."

The team leader of the original paper says he remains confident that plants are making their own methane, although soils clearly also contribute. "It's getting clearer that living vegetation is maybe playing a more active role in emitting methane to the atmosphere than we previously thought," says Frank Keppler, a geochemist at the Max Planck Institute for Chemistry in Mainz, Germany. Amanda Mascarelli

\footnotetext{
1. Keppler, F., Hamilton, J. T. G., Braß, M. \& Röckmann, T. Nature 439, 187-191 (2006).

2. Rice, A. L. et al. Geophys. Res. Lett.

doi:10.1029/2009GL041565 (2010)

3. Nisbet, R. E. R. et al. Proc. R. Soc. B 276, 1347-1354 (2009)
}

Physics, builds on a well-established idea. Global temperatures were relatively stable in the decades leading up to the 1970 s, even as fossil-fuel consumption shot up. Then industrialized countries began curbing $\mathrm{SO}_{2}$ and $\mathrm{NO}_{x}$ to reduce acid rain and protect public health - and temperatures increased rapidly. The latest work, led by Drew Shindell at NASA's Goddard Institute for Space Studies in New York, looks at how the climate effects of air pollutants and greenhouse gases could play out over time and geography.

The study analysed a suite of scenarios for the years 2000 to 2080 , mixing annual rates of powerplant growth from $5 \%$ to $10 \%$ with various controls on $\mathrm{SO}_{2}$ and $\mathrm{NO}_{x}$ pollution. $\mathrm{SO}_{2}$ is a precursor to sulphate aerosols and dominates the cooling effect, which varies depending on when plants adopt pollution controls. The sooner controls are put in place, the sooner the warming potential of $\mathrm{CO}_{2}$ kicks in.
In one scenario assuming rapid growth in coal power with pollution controls phased in between 2040 and 2060, the effect of aerosols from the plants outweighs the effect of their $\mathrm{CO}_{2}$ until the year 2046, when the $\mathrm{CO}_{2}$ effect catches up and then overtakes aerosols. But the effect isn't uniform: the $\mathrm{SO}_{2}$ emissions produce a net cooling across much of the Northern Hemisphere. The Southern Hemisphere and the Arctic see fewer aerosols and, because $\mathrm{CO}_{2}$ has global effects, they exhibit net warming.

How quickly China and India will move to clean up their coal emissions is unclear. In the past few years China has been aggressively installing $\mathrm{SO}_{2}$ scrubbers on many of its power plants in an attempt to improve air quality and protect public health. But some experts have questioned whether those scrubbers are being used properly - or even turned on. Jeff Tollefson 